\title{
In situ measurements of isoprene and monoterpenes within a south-east Asian tropical rainforest
}

\author{
C. E. Jones ${ }^{1,}$, J. R. Hopkins ${ }^{1,2}$, and A. C. Lewis ${ }^{1,2}$ \\ ${ }^{1}$ Department of Chemistry, University of York, Heslington, York, YO10 5DD, UK \\ ${ }^{2}$ National Centre for Atmospheric Science (NCAS), Department of Chemistry, University of York, Heslington, York, \\ YO10 5DD, UK \\ * now at: Department of Applied Chemistry, Faculty of Urban Environmental Sciences, Tokyo Metropolitan University, \\ Minami-osawa 1-1, Hachioji-shi, Tokyo 192-0397, Japan
}

Received: 1 December 2010 - Published in Atmos. Chem. Phys. Discuss.: 17 January 2011

Revised: 12 May 2011 - Accepted: 12 June 2011 - Published: 19 July 2011

\begin{abstract}
Biogenic volatile organic compounds (BVOCs) emitted from tropical rainforests comprise a substantial fraction of global atmospheric VOC emissions, however there are only relatively limited measurements of these species in tropical rainforest regions. We present observations of isoprene, $\alpha$-pinene, camphene, $\Delta-3$-carene, $\gamma$-terpinene and limonene, as well as oxygenated VOCs (OVOCs) of biogenic origin such as methacrolein, in ambient air above a tropical rainforest in Malaysian Borneo during the Oxidant and Particle Photochemical Processes above a south-east Asian tropical rainforest (OP3) project in 2008. Daytime composition was dominated by isoprene, with an average mixing ratio of the order of $\sim 1 \mathrm{ppb}$. $\gamma$-terpinene, limonene and camphene were the most abundant monoterpenes, with average daytime mixing ratios of 102, 71 and $66 \mathrm{ppt}$ respectively, and with an average monoterpene toisoprene ratio of 0.3 during sunlit hours, compared to 2.0 at night. Limonene and camphene abundances were seen to be related to both temperature and light conditions. In contrast, $\gamma$-terpinene emission continued into the late afternoon/evening, under relatively low temperature and light conditions. The contributions of isoprene, monoterpenes and other classes of VOC to the volatile carbon budget and $\mathrm{OH}$ reactivity have been summarised for this rainforest location. We observe good agreement between surface and aircraft measurements of boundary layer isoprene and methacrolein above the natural rainforest, suggesting that the ground-level observations are broadly representative of isoprene emissions from this region.
\end{abstract}

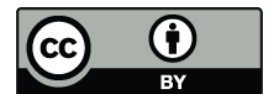

Correspondence to: J. R. Hopkins (jim.hopkins@york.ac.uk)

\section{Introduction}

Emissions of volatile organic compounds (VOCs) affect the oxidising capacity of the atmosphere (Kesselmeier et al., 2000), radiative forcing (through formation of secondary organic aerosol, Padhy and Varshney, 2005) and the global carbon cycle (Kuhn et al., 2002; Fuentes et al., 2000). VOCs scavenge oxidants such as the hydroxyl radical $(\mathrm{OH})$, ozone $\left(\mathrm{O}_{3}\right)$ and the nitrate radical $\left(\mathrm{NO}_{3}\right)$ (Atkinson and Arey, 2003), and in polluted, high $\mathrm{NO}_{\mathrm{x}}\left(\mathrm{NO}\right.$ and $\left.\mathrm{NO}_{2}\right)$ environments, VOC emissions lead to net tropospheric $\mathrm{O}_{3}$ production through catalytic reactions between oxidised VOC derivatives (peroxy radicals) and NO (Atkinson and Arey, 2003; Lelieveld et al., 2008).

Biogenic VOCs (BVOCs) such as isoprene, monoterpenes and sesquiterpenes are thought to provide the largest fraction $(>90 \%)$ of the total global non-methane VOC source term (Greenberg et al., 1999), with a total BVOC flux of the order of $1100 \mathrm{Tg} \mathrm{C} \mathrm{yr}^{-1}$ (Guenther et al., 1995; Simpson et al., 1999), compared to $50-100 \mathrm{Tg} \mathrm{C} \mathrm{yr}^{-1}$ anthropogenic VOCs (Holzke et al., 2006). Biosynthesis of isoprene and monoterpenes occurs within plants via the precursors dimethylallyl pyrophosphate (DMAPP) and isopentenyl pyrophosphate (IPP) (Fuentes et al., 2000), and has been linked with a number of physiological processes such as temperature regulation, reducing drought-induced stress and promotion of flowering (Kesselmeier and Staudt, 1999). BVOC emissions (by mass) are often dominated by isoprene (Guenther et al., 2000), and estimates of the annual global isoprene flux are comparable with annual global methane emissions (Wildermuth and Fall, 1996; Sharkey and Yeh, 2001).

Published by Copernicus Publications on behalf of the European Geosciences Union. 
BVOC emissions from the tropics are considered to have a disproportionately large impact upon the chemistry of the atmosphere (IPCC, 2001), since deep convection in this region drives rapid transport of ground level emissions to higher altitudes, such that local emissions may become distributed over a relatively broad area. In fact, more than $70 \%$ of BVOCs are thought to originate from the tropics (Karl et al., 2007), yet there have been only a limited number of BVOC measurements within this region, and very few of these datasets include in situ measurements of a comprehensive range of monoterpenes (Kesselmeier et al., 2000; Kuhn et al., 2002; Wilske et al., 2007; Saxton et al., 2007). The majority of previous tropical BVOC datasets are for Amazonia (Kesselmeier et al., 2000), whilst BVOC measurements from South-East Asia are more sparse (Hewitt et al., 2010). Since BVOC emissions from vegetation are strongly speciesdependent, increasing the spatial and temporal range of measurements of these gases is fundamental to achieving improved characterisation of their local, regional and global scale impact on the chemistry of the atmosphere.

Here we present in situ measurements of isoprene and the monoterpenes $\alpha$-pinene, camphene, $\Delta$-3-carene, $\gamma$-terpinene and limonene, together with a range of other $\mathrm{C}_{2}-\mathrm{C}_{5}$ VOCs and OVOCs, in ambient air at the Bukit Atur Global Atmosphere Watch (GAW) station within the Danum Valley rainforest in Sabah, Borneo, as part of the Oxidant and Particle Photochemical Processes above a South-East Asian tropical rainforest (OP3) campaign. We also present measurements of selected VOCs (including isoprene) from an aircraft platform, which reveal regional variations in VOC concentrations in response to changes in land use across Malaysian Borneo.

\section{Methods}

Gas chromatography with flame ionization detection (GCFID) was used to provide automated continuous hourly measurements of selected VOCs in ambient air at the Bukit Atur GAW station, located in the Danum Valley rainforest conservation area in Sabah, Borneo $\left(4^{\circ} 58^{\prime} 49.33^{\prime \prime} \mathrm{N}\right.$, $117^{\circ} 50^{\prime} 39.05^{\prime \prime} \mathrm{E}, 426 \mathrm{~m}$ a.s.1.). The site was located in a clearing at the top of a hill, above most of the surrounding rainforest, and air was sampled for analysis of VOCs from $\sim 5 \mathrm{~m}$ a.g.l. The ground-based component of the OP3 project consisted of three measurement phases during 2008 (Hewitt et al., 2010), and in situ measurements of VOCs at Bukit Atur were made during two of these - from 7 April to 1 May (OP3-I), and 23 June to 20 July (OP3-III). During OP3-III, aircraft-based regional VOC measurements were made concurrently with the ground-based observations.

Volatile trace gases were pre-concentrated from 11 air samples by pumping several litres of ambient air per minute from $5 \mathrm{~m}$ a.g.l. through a $\sim 10 \mathrm{~m}$ long $1 / 2^{\prime \prime}$ id manifold, and sub-sampling $100 \mathrm{ml} \mathrm{min}^{-1}$ air from this manifold through a
$1 / 4^{\prime \prime}$ id $1 \mathrm{~m}$ long stainless steel line to a Peltier-cooled multibed carbon-based chemical adsorbent trap (held at $-20^{\circ} \mathrm{C}$ ) for $10 \mathrm{~min}$ periods. The trap was subsequently flushed with helium for $2 \mathrm{~min}$ to remove moisture and methane, before desorption of the volatile components into the helium carrier gas stream by heating to $325^{\circ} \mathrm{C}$. Chromatographic separation was achieved using a dual-column Agilent 6890 GC system, which facilitates simultaneous analysis of both non-methane hydrocarbons (NMHCs), which were separated using a $50 \mathrm{~m}$ aluminium oxide $\left(\mathrm{Al}_{2} \mathrm{O}_{3}\right)$ porous layer open tubular (PLOT) column, and oxygenated VOCs (OVOCs) and monoterpenes, which were separated using two $10 \mathrm{~m}$ LOWOX columns in series. Following desorption, the analytes were split between the PLOT and LOWOX columns, with each column coupled to a FID. Calibration of the majority of VOCs was achieved using an Apel Reimer certified 54 component gas standard (serial number CC236306), however in the field the monoterpenes (which suffer from degradation in gas canisters) were calibrated based upon the relationship between the FID response to each monoterpene relative to toluene (empirically derived by liquid injection calibrations prior to field studies). Individual VOCs were identified on the basis of their GC retention times, which were monitored periodically by analysis of a gas standard (Apel Reimer) and pure liquid injections during the field measurement period. The $1 \sigma$ measurement uncertainties (calculated as the root sum of squares of the measurement precision and all quantifiable experimental uncertainties, such as those associated with flow rates and certified gas standard concentrations) were between $8-13 \%$ for the majority of VOCs, and 11-20\% for the monoterpenes. Further details of the NMHC and OVOC sampling and GCFID separation, analysis and calibration using this system are given elsewhere (Hopkins et al., 2002, 2011).

The monoterpenes analysed using this system were $\alpha$-pinene, camphene, $\Delta$-3-carene, $\gamma$-terpinene, limonene and $\beta$-pinene. Analysis of pure monoterpene liquids in laboratory tests showed that in some cases a small amount of inter-conversion between several monoterpene isomers occurred within the system, presumably during preconcentration on the adsorbent trap. There was no significant degradation/inter-conversion of camphene, $\Delta$-3-carene or $\gamma$ terpinene, however $\sim 8 \%$ of limonene injected into the system was converted to $\gamma$-terpinene, and $\alpha$-pinene experienced the most degradation, with $\sim 10 \%$ converted to camphene and $\sim 5 \%$ converted to limonene (Hopkins et al., 2011). Since these in-system isomerizations were repeatable, the reported monoterpene mixing ratios in ambient air samples have been corrected accordingly. It should be noted that although $\beta$-pinene was detected in standards, it was not detected in ambient air samples in the Danum Valley rainforest. A summary of the VOCs and OVOCs routinely monitored during this study is given in Table 1. 
Table 1. Mean average daytime VOC mixing ratios observed within the natural rainforest at Bukit Atur, and in air samples collected above the natural rainforest and oil palm plantations. In each case the range of observed daytime mixing ratios in ppt are given in brackets (5th and 95th percentiles) and the median mixing ratio is shown in curly brackets. Note that some VOCs routinely measured by the ground-based instrument, including acetaldehyde and benzene, are not reported as a result of instrumentation difficulties experienced during the OP3 field campaign.

\begin{tabular}{|c|c|c|c|c|}
\hline \multirow[t]{2}{*}{ VOC } & \multirow[b]{2}{*}{$\begin{array}{l}\text { Limit of } \\
\text { detection } \\
(\mathrm{ppt})\end{array}$} & \multicolumn{3}{|c|}{ Mixing ratios (ppt) } \\
\hline & & $\begin{array}{l}\text { Bukit Atur - } \\
\text { natural rain- } \\
\text { forest (ground } \\
\text { level) }\end{array}$ & $\begin{array}{l}\text { Aircraft natural } \\
\text { rainforest }\end{array}$ & $\begin{array}{l}\text { Aircraft oil } \\
\text { palm }\end{array}$ \\
\hline Isoprene & 1 & $\begin{array}{l}1058\{889\} \\
(50-2474)\end{array}$ & $\begin{array}{l}1219\{767\} \\
(252-4664)\end{array}$ & $\begin{array}{l}4215\{3870\} \\
(414-10522)\end{array}$ \\
\hline$\alpha$-pinene & 3 & $\begin{array}{l}24\{20\} \\
(9-40)\end{array}$ & - & - \\
\hline Camphene & 3 & $\begin{array}{l}66\{58\} \\
(14-129)\end{array}$ & - & - \\
\hline$\Delta-3$-carene & 3 & $\begin{array}{l}22\{20\} \\
(9-41)\end{array}$ & - & - \\
\hline$\gamma$-terpinene & 3 & $\begin{array}{l}102\{99\} \\
(53-166)\end{array}$ & - & - \\
\hline Limonene & 3 & $\begin{array}{l}71\{68\} \\
(26-127)\end{array}$ & - & - \\
\hline Methacrolein & 3 & $\begin{array}{l}106\{86\} \\
(42-234)\end{array}$ & $\begin{array}{l}105\{85\} \\
(23-268)\end{array}$ & $\begin{array}{l}221\{173\} \\
(42-517)\end{array}$ \\
\hline Methanol & 40 & $\begin{array}{l}1798\{1637\} \\
(933-2807)\end{array}$ & $\begin{array}{l}3450\{3098\} \\
(1131-6593)\end{array}$ & $\begin{array}{l}2907\{2725\} \\
(681-5278)\end{array}$ \\
\hline Acetone & 9 & $\begin{array}{l}426\{432\} \\
(212-766)\end{array}$ & $\begin{array}{l}1332\{1108\} \\
(694-2486)\end{array}$ & $\begin{array}{l}1130\{918\} \\
(588-2494)\end{array}$ \\
\hline Methyl vinyl ketone + Ethanol & 4 & $\begin{array}{l}450\{358\} \\
(188-722)\end{array}$ & - & - \\
\hline Ethene & 7 & $\begin{array}{l}77\{70\} \\
(36-132)\end{array}$ & $\begin{array}{l}147\{127\} \\
(83-237)\end{array}$ & $\begin{array}{l}186\{155\} \\
(80-411)\end{array}$ \\
\hline Propene & 3 & $\begin{array}{l}47\{31\} \\
(19-56)\end{array}$ & $\begin{array}{l}23\{23\} \\
(14-38)\end{array}$ & $\begin{array}{l}34\{25\} \\
(13-90)\end{array}$ \\
\hline iso-butene & 1 & $\begin{array}{l}111\{109\} \\
(63-175)\end{array}$ & $\begin{array}{l}12\{11\} \\
(6-20)\end{array}$ & $\begin{array}{l}12\{11\} \\
(7-17)\end{array}$ \\
\hline Acetylene & 3 & $\begin{array}{l}121\{120\} \\
(71-182)\end{array}$ & $\begin{array}{l}152\{146\} \\
(84-222)\end{array}$ & $\begin{array}{l}181\{157\} \\
(112-299)\end{array}$ \\
\hline Ethane & 9 & $\begin{array}{l}368\{344\} \\
(222-560)\end{array}$ & $\begin{array}{l}320\{296\} \\
(250-420)\end{array}$ & $\begin{array}{l}325\{309\} \\
(253-456)\end{array}$ \\
\hline Propane & 3 & $\begin{array}{l}173\{133\} \\
(24-378)\end{array}$ & $\begin{array}{l}94\{95\} \\
(46-144)\end{array}$ & $\begin{array}{l}93\{91\} \\
(65-128)\end{array}$ \\
\hline n-pentane & 1 & $\begin{array}{l}26\{22\} \\
(13-45)\end{array}$ & $\begin{array}{l}15\{11\} \\
(4-28)\end{array}$ & $\begin{array}{l}14\{13\} \\
(7-24)\end{array}$ \\
\hline iso-pentane & 1 & $\begin{array}{l}33\{28\} \\
(9-71)\end{array}$ & $\begin{array}{l}17\{16\} \\
(5-30)\end{array}$ & $\begin{array}{l}20\{18\} \\
(9-37)\end{array}$ \\
\hline cyclo-pentane & 1 & $\begin{array}{l}9\{9\} \\
(5-14)\end{array}$ & $\begin{array}{l}6\{6\} \\
(5-8)\end{array}$ & $\begin{array}{l}7\{7\} \\
(5-8)\end{array}$ \\
\hline
\end{tabular}

During the June/July phase of the OP3 experiment (OP3III), an almost identical Perkin Elmer dual channel GC-FID instrument was used to analyse whole air samples collected aboard the Facility for Airborne Atmospheric Measurements (FAAM) BAe146 research aircraft. During the first phase of the OP3 project (OP3-I) the system was briefly deployed at the Bukit Atur GAW station alongside the ground-based Agilent instrument. The excellent agreement in atmospheric iso- prene mixing ratios determined by the two instruments when co-located at the GAW station (see Fig. 1) has enabled direct comparisons between data collected at the ground and those collected during flights in the region. Air samples taken on board the aircraft were not analysed for monoterpenes, as their stability in canisters has not been tested, and the instrument was not optimised for monoterpene analysis. 


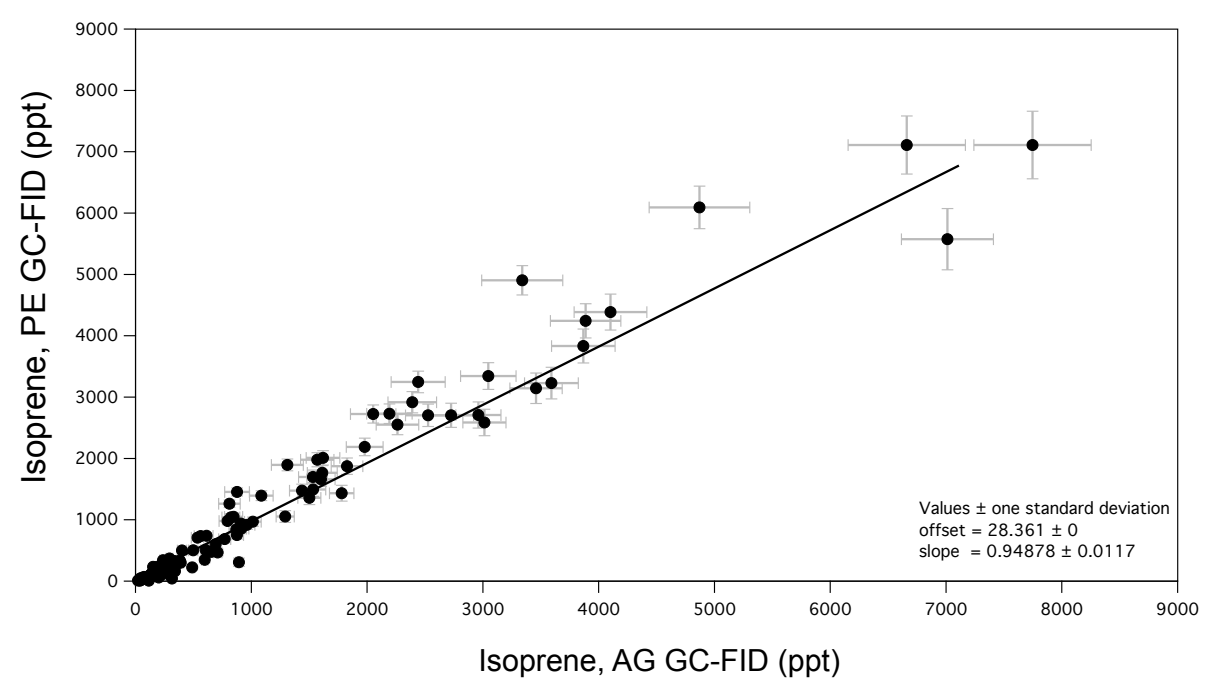

Fig. 1. Correlation between isoprene mixing ratios in ambient air quantified by the independent Agilent (AG) and Perkin Elmer (PE) GCFID instruments at the Bukit Atur GAW station in April 2008. Note only mixing ratios derived from simultaneous measurements (sampling periods within $\pm 5 \mathrm{~min}$ ) were used for this comparison.

\section{Results and discussion}

\subsection{Summary of ground-based and aircraft-based VOC measurements}

Table 1 summarises the VOC atmospheric mixing ratios in air at ground-level at the Bukit Atur rainforest site, and in air samples collected from the aircraft platform. To enable some comparability, the daytime (06:00 a.m.-06:00 p.m., Borneo local time) range and mean average mixing ratios are shown in both cases (since no night-time air samples were collected on board the aircraft), and ground-based data refers to the second measurement period (concurrent with the aircraft study) only. The airborne measurements have been separated according to whether the air samples were collected above the natural rainforest, or over oil palm plantations, which now cover vast areas of Malaysian Borneo (Hewitt et al., 2009).

The average daytime mixing ratios of isoprene and one of its oxidation products, methacrolein, at ground-level were in good agreement with the levels observed in air above the natural rainforest. This suggests that the Bukit Atur site may be considered broadly representative of this natural forest region, with respect to isoprene emission and oxidation chemistry. However, significantly higher maximum daytime isoprene mixing ratios were observed in the aircraft samples (almost double the maximum mixing ratios observed at groundlevel), indicating the presence of local isoprene "hotspots" within the natural rainforest, and/or suppression of ambient isoprene at ground-level as a consequence of localised pollution (see below).

Isoprene was highly elevated in air above the oil palm plantations, with an average daytime mixing ratio approx- imately four times higher compared to that above the surrounding natural rainforest, demonstrating that man-made land use change may potentially have significant implications for atmospheric composition (Hewitt et al., 2009).

The daily maximum isoprene mixing ratio was generally higher and more variable during the first measurement period in April (OP3-I) compared to the June-July period (OP3-III) (see Fig. 2). A lack of any marked seasonality in the Danum Valley conservation area has been previously reported for 2008 (Hewitt et al., 2010), hence significant seasonal differences were not anticipated. Given the low wind speeds and relatively short atmospheric lifetimes for these BVOCs, their mixing ratios at Bukit Atur are considered to result predominantly from local emissions, however, there may also have been some influence from regional air masses reaching the site, and whilst the station was influenced by air from most directions during OP3-I, during OP3-III trajectories were consistently from the south (Hewitt et al., 2010).

A further potentially important factor in the apparent suppression of isoprene during OP3-III was a period of local pollution in the form of $\mathrm{NO}$ (median peak noontime $\mathrm{NO}$ was $\sim 0.08 \mathrm{ppb}$ and $\sim 0.14 \mathrm{ppb}$ during OP3-I and OP3-III, respectively, Pike et al., 2010), which gave rise to elevated $\mathrm{OH}$ mixing ratios (median midday values of $\sim 1.6 \times 10^{6} \mathrm{molec} \mathrm{cm}^{-3}$ OH for OP3-I, compared to $\sim 3.4 \times 10^{6} \mathrm{molec} \mathrm{cm}^{-3}$ during OP3-III; http://badc.nerc.ac.uk/browse/badc/op3/data). At midday, we estimate that this would result in a $\sim 50 \%$ decrease in the atmospheric lifetime of isoprene during OP3-III compared to OP3-I, whilst the $24 \mathrm{~h}$-averaged isoprene and monoterpene lifetimes would be reduced by approximately $\sim 30 \%$. 

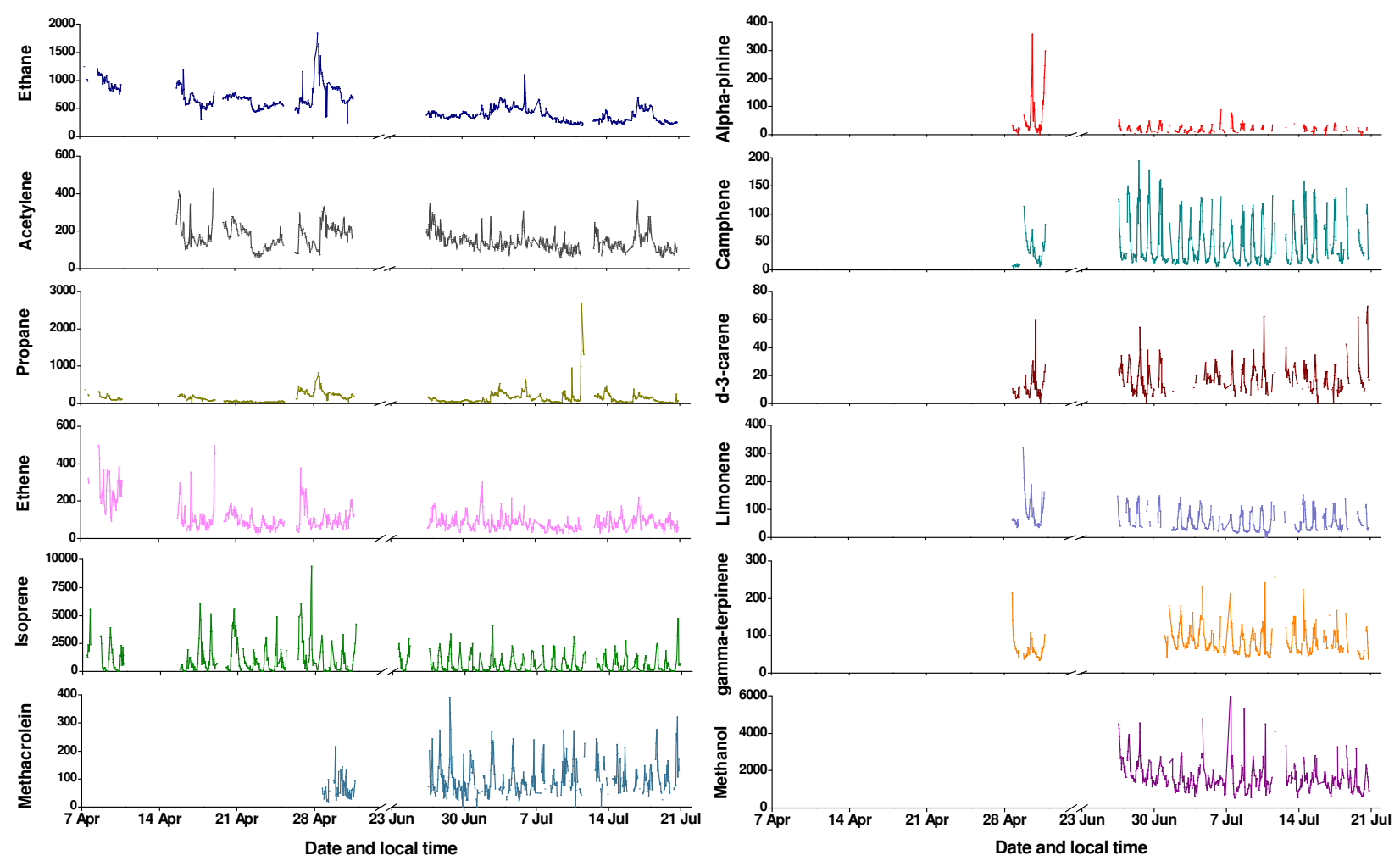

Fig. 2. Time-resolved measurements of isoprene and its oxidation product methacrolein, the monoterpenes $\alpha$-pinene, camphene, $\Delta-3-$ carene, limonene and $\gamma$-terpinene, methanol, and selected other VOCs thought to be of primarily anthropogenic origin (ethane, acetylene and propane) at the ground-based site at Bukit Atur during April 2008 (OP3-I) and June-July 2008 (OP3-III). Only limited monoterpene and OVOC data is shown from the first measurement period, due to instrument failures.

We infer therefore, that the isoprene and monoterpene mixing ratios observed during OP3-III were likely suppressed to some extent by higher $\mathrm{OH}$ levels during this period. Whilst this means that the ambient air BVOC mixing ratios reported from OP3-III likely represent an underestimate of the levels that might be expected above the pristine rainforest in this region, the diurnal variability and relative contributions of primary emitted BVOCs to the carbon budget and boundary layer chemistry remain broadly representative of the Danum Valley conservation area.

Levels of isoprene and several other VOCs such as acetone are generally comparable with the lower range of the corresponding mixing ratios reported by Langford et al. (2010), based on their measurements from a height of $75 \mathrm{~m}$ at the Bukit Atur site during OP3-III. Langford et al. (2010) report an average isoprene mixing ratio of $1.4 \mathrm{ppb}$ compared to the average of $0.9 \mathrm{ppb}$ (including night time measurements) from this work. Since there were no $\mathrm{OH}$ measurements colocated with the Langford et al. observations, we can only speculate as to the reason for the differences between the two datasets. However, we feel that the most probable explanation is that the localised pollution and associated elevated $\mathrm{OH}$ mixing ratios experienced at ground level suppressed VOC mixing ratios in the local area where our observations were made, whilst the larger sample footprint of the Langford et al. (2010) measurements meant that the impact of local pollution upon VOC mixing ratios was less marked in those observations. This is consistent with the closer agreement between the isoprene mixing ratios observed by the two instruments during the first measurement period, OP3-I (for which both Langford et al. (2010) and this work determined campaign mean average isoprene mixing ratios of $1.1 \mathrm{ppb}$ ).

\subsection{Factors controlling ground-level ambient BVOC mixing ratios within the natural rainforest}

Several previous studies have demonstrated considerable diurnal variability in the release of isoprene and monoterpenes from vegetation, with maximum emissions occurring around midday (Fuentes et al., 2000; Kuhn et al., 2002). The diurnal variation in boundary layer isoprene is generally attributed to an emission pathway dependent upon both light and temperature (Kuhn et al., 2002). Monoterpene release from broadleaved species is thought to be controlled by a similar dual light and temperature dependence, whilst there is evidence to suggest that some monoterpenes may be stored within 

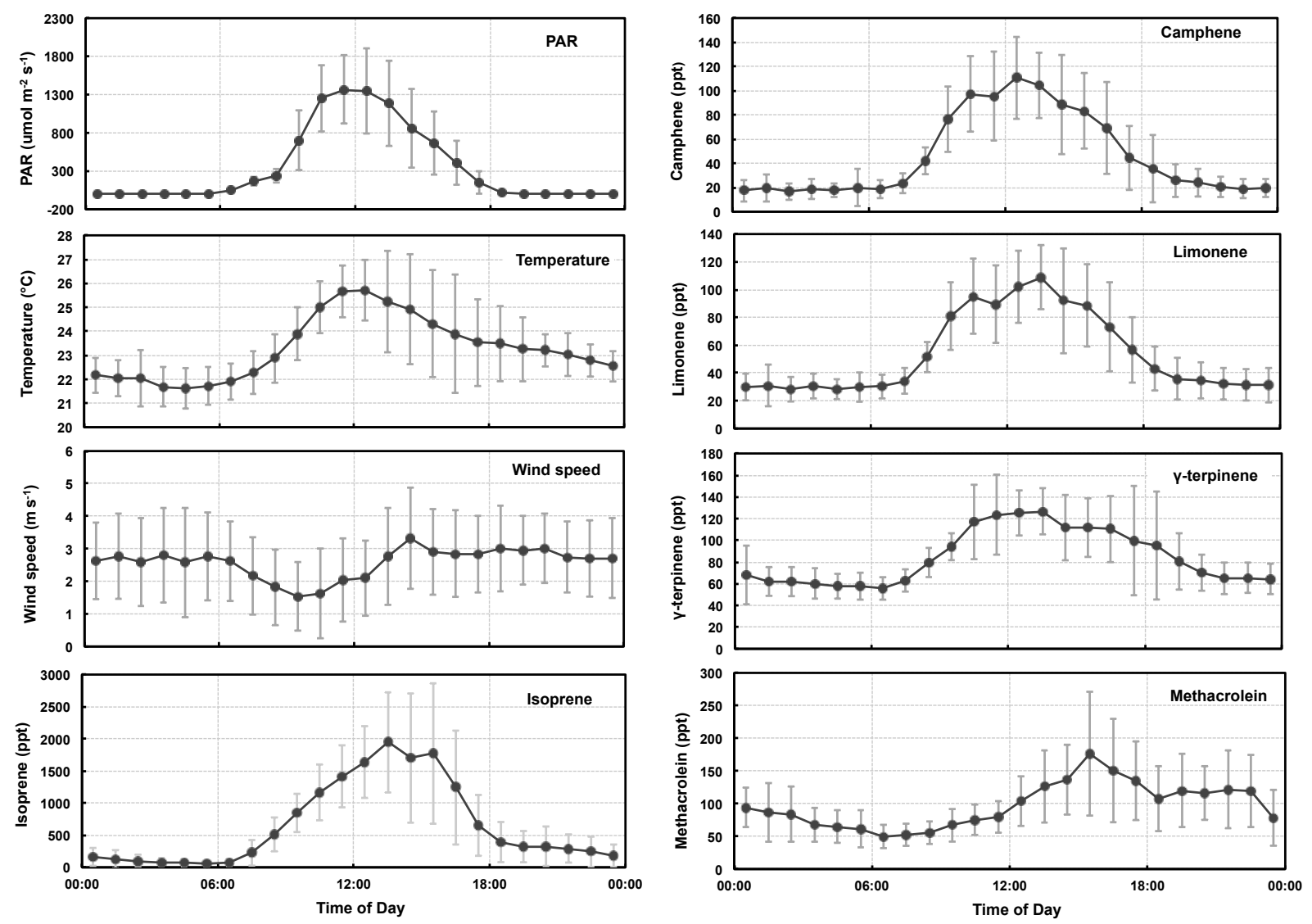

Fig. 3. Diurnal average PAR and temperature profiles and mixing ratios of isoprene, the three most abundant monoterpenes (limonene, $\gamma$-terpinene and camphene) and methacrolein. Note PAR, temperature and wind speed measurements correspond to a height of $75 \mathrm{~m}$.

coniferous plants, with release from these reservoirs regulated exclusively by temperature, and independent of light levels (Kuhn et al., 2002; Noe et al., 2006; Wilske et al., 2007).

A strong diurnal signature was observed in the isoprene and monoterpene mixing ratios at Bukit Atur (see Figs. 2 and 3), and whilst daytime BVOC emissions were dominated by isoprene, the monoterpenes were found to persist at night, when, in the absence of sunlight, isoprene mixing ratios dropped to as low as $\sim 0.05$ pptv (Fig. 3). In fact, the average monoterpene to isoprene ratio increased from $\sim 0.3$ during the day (06:00 a.m.-06:00 p.m.) to $\sim 2.0$ at night (06:00 p.m.-06:00 a.m.). The daytime monoterpene to isoprene ratio is in fairly good agreement with the average \{total monoterpene\}/isoprene emission ratio derived from flux measurements made during the same period at Bukit Atur (0.23 \pm 0.3 , Langford et al., 2010), as well as with emission ratios from other studies (Guenther et al., 2008). The marked increase in the ambient monoterpene/isoprene ratio at night was not reflected in the relative emission rates measured at Bukit Atur, however the flux measurements were made at a height of $75 \mathrm{~m}$ above ground-level (compared to $5 \mathrm{~m}$ for the "ground-level" measurements reported here), and there is evidence to suggest that at night the $75 \mathrm{~m}$ platform was de-coupled from the boundary layer (Pearson et al., 2010; Hewitt et al., 2010). Notably there are some distinct differences between the isoprene diurnal profiles measured at ground level (this work) and at $75 \mathrm{~m}$ (Langford et al., 2010), during the same period. Isoprene levels above the canopy appear to increase more rapidly following sunrise compared to the ground level mixing ratios, and decrease more gradually in the afternoon, presumably as a result of differences in light levels and mixing rates. However, observations at both heights demonstrate an asymmetric isoprene profile, with maximum mixing ratios in the early afternoon.

Figure 3 shows the hourly averaged concentrations of isoprene, methacrolein and the three most abundant monoterpenes (camphene, limonene and $\gamma$-terpinene), to give diurnal profiles derived from all measurements between 23 June20 July 2008, together with the average daily photosynthetically active radiation (PAR), temperature and wind speed profiles. Figure 4 shows the correlations of isoprene and the monoterpenes with temperature and PAR. The concentration profiles and correlation plots (Figs. 3 and 4) indicate that isoprene, limonene and camphene were well correlated with both temperature and PAR, whilst $\gamma$-terpinene showed 

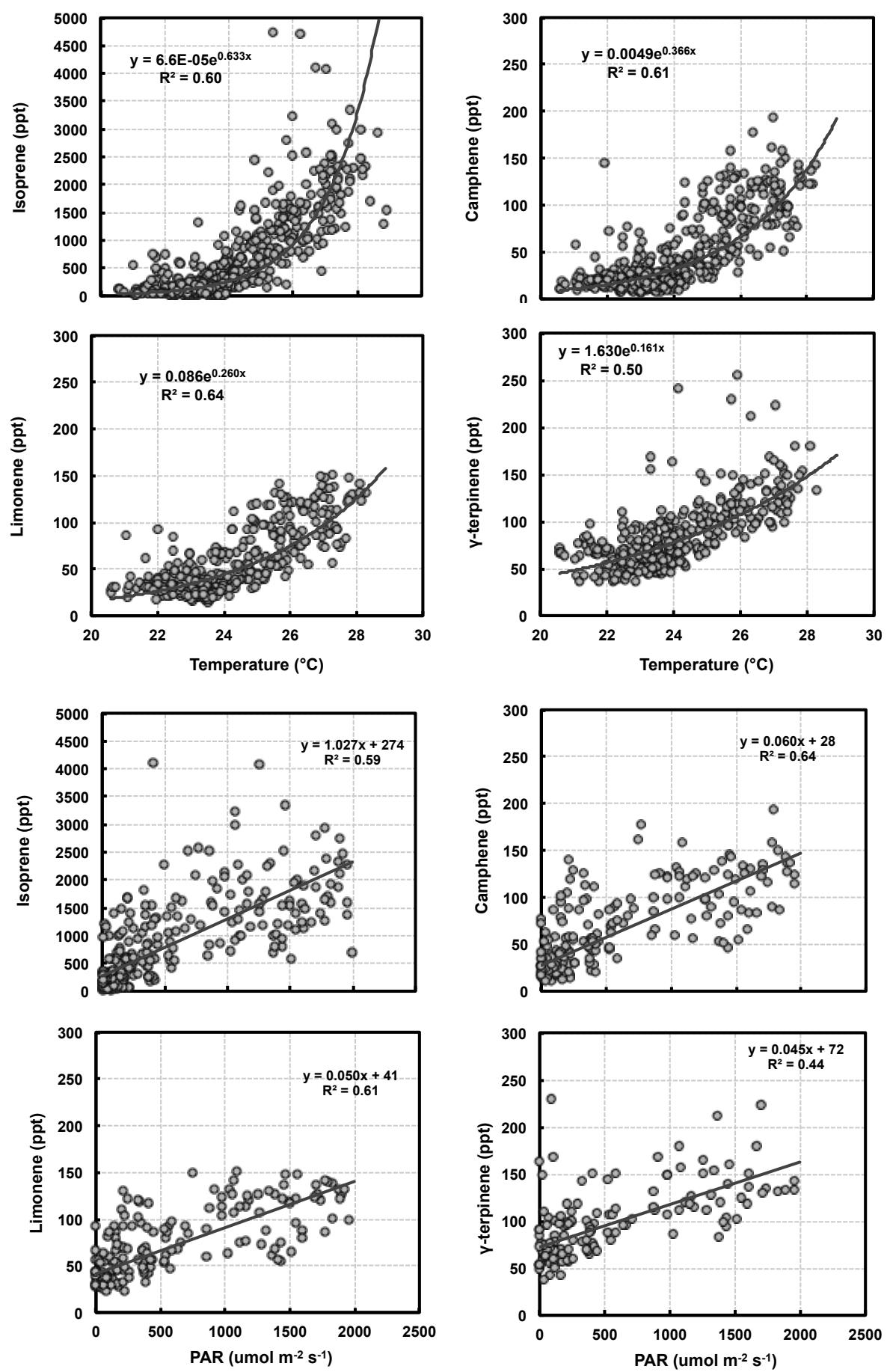

Fig. 4. Plots to show the correlations between isoprene, limonene, camphene and $\gamma$-terpinene vs. ambient air temperature and vs. PAR.

a more moderate dependence upon both factors. Notably, the $\gamma$-terpinene mixing ratio remained significantly elevated during the late afternoon/evening, well after PAR and temperature had started to decrease, and remained above $80 \mathrm{ppt}$ (on average) for $1-2 \mathrm{~h}$ after PAR had reached zero (Fig. 3). Since $\gamma$-terpinene is one of the shorter-lived monoterpenes (typical lifetime $\sim 45 \mathrm{~min}$, Atkinson and Arey, 2003), persis- tence into the late afternoon/evening suggests that leaf emissions were still occurring at this time, even under very low light levels. Although the $\gamma$-terpinene mixing ratio did eventually decrease at night, the difference between day and night time concentrations was not as extreme as for isoprene and the other monoterpenes. 
Table 2. Spearman's rank correlation coefficients to demonstrate the degree of correlation between VOC mixing ratios with air temperature $\left({ }^{\circ} \mathrm{C}\right)$ and PAR $\left(\mu \mathrm{mol} \mathrm{m}{ }^{-2} \mathrm{~s}^{-1}\right)$. Correlations with PAR are based upon 425 data pairs; temperature correlations are based on 534 data pairs (isoprene, acetylene and ethane) and 478 (monoterpenes and methacrolein).

\begin{tabular}{lrrrr}
\hline & Air temperature & PAR (all data) & PAR (00:00-12:00) & PAR (12:00-00:00) \\
\hline isoprene & 0.78 & 0.71 & 0.64 & 0.79 \\
$\alpha$-pinene & 0.70 & 0.67 & 0.53 & 0.68 \\
camphene & 0.71 & 0.68 & 0.61 & 0.78 \\
$\Delta$-3-carene & 0.53 & 0.34 & 0.28 & 0.43 \\
$\gamma$-terpinene & 0.67 & 0.61 & 0.55 & 0.69 \\
limonene & 0.70 & 0.72 & 0.63 & 0.79 \\
methacrolein & 0.43 & 0.05 & -0.09 & 0.19 \\
acetylene & -0.10 & -0.24 & -0.19 & -0.27 \\
ethane & -0.17 & -0.05 & -0.05 & -0.05 \\
Air temperature & - & 0.58 & 0.52 & 0.70 \\
\hline
\end{tabular}

Table 2 summarises the Spearman's rank correlation coefficients, which quantify the extent of correlation between each of the BVOCs with air temperature and PAR (where a correlation coefficient of +1 or -1 indicates a perfect correlation, and a coefficient of 0 indicates no correlation). The Spearman's rank correlation coefficient was chosen to express the extent of correlation between VOCs, temperature and PAR since there were data points where some VOC mixing ratios were below the instrument detection limit, and as such it is appropriate to use a non-parametric test for correlation, even when the sample follows a Gaussian distribution (Motulsky, 1995).

Isoprene was strongly correlated with temperature, whilst the statistical test on all measurements indicates a comparatively weaker correlation with PAR. Previous studies have established light-dependent emission pathways for isoprene (e.g. Fuentes et al., 2000), and the slightly weaker relationship with PAR apparent in our ambient air observations may be a consequence of light-dependent isoprene destruction (via reaction with photochemically produced $\mathrm{OH}$, Atkinson, 1997; Calvert et al., 2000) competing with light-dependent emission. The isoprene mixing ratio peaked just after midday, slightly later than the maximum PAR; concurrent $\mathrm{OH}$ observations at Bukit Atur (Whalley et al., 2011) show that $\mathrm{OH}$ peaked at local noon, suggesting that although maximum isoprene emission may have occurred around midday inline with maximum PAR, rapid removal of isoprene by $\mathrm{OH}$ suppressed ambient concentrations during this time. In addition, Grinspoon et al. (1991) suggest that isoprene emission from velvet pine (Mucuna sp.) is dependent upon the product(s) of the light-dependent reactions of photosynthesis, rather than being directly linked to photosynthesis itself, and as such maximum daily isoprene emissions might be delayed slightly following peak photosynthesis. Both scenarios are consistent with the relatively lower levels of ambient isoprene observed in the late morning-midday period compared to equivalent light conditions during the afternoon, which reduces the strength of the correlation between isoprene levels and PAR for this period. In contrast, measurements made between midday and midnight demonstrate a much stronger correlation between isoprene and PAR, comparable to the correlation between isoprene with temperature (Table 2). Figure 5 shows the isoprene-PAR correlations separated into the midnight-midday and post middaymidnight periods, and demonstrates that the isoprene mixing ratios measured in the morning were generally reduced compared to values in the afternoon, for equivalent PAR. In contrast, the equivalent plot of isoprene vs temperature (Fig. 5b) shows no significant difference between the pre-midday and post-midday correlations. Since ozone concentrations were very low (typically $\sim 5$ ppb, Hewitt et al., 2010), scavenging of BVOCs by ozone was presumed to be insignificant compared to loss by reaction with $\mathrm{OH}$.

With the exception of limonene, the monoterpene correlation plots and correlation coefficients derived from all measurements are generally more consistent with a temperaturecontrolled emission pathway, and suggest a relatively weaker dependence upon light levels (Fig. 4 and Table 2). The correlation coefficients derived solely from the post-midday measurements suggest that emissions of limonene and camphene, in particular, may also be influenced to some extent by light levels (Table 2). This is consistent with changes in the relative atmospheric monoterpene composition according to the time of day (Fig. 6) and with the treatment of monoterpenes in the model study of Pugh et al. (2010), which assumes a light-dependent emission pathway. However, caution must be exercised in the interpretation of these statistical tests, since temperature and PAR were themselves reasonably well correlated ( $\rho=0.58$ for all measurements, see Table 2), particularly in the midday-midnight period $(\rho=0.70)$. As such, the stronger correlations between both limonene and camphene with PAR after midday may be, at least in part, simply an artefact of the PAR vs. temperature correlation. 
a)

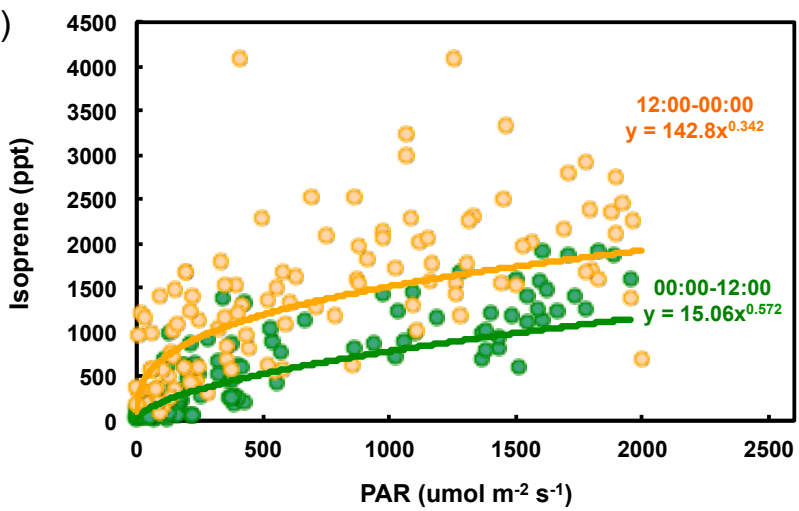

b)

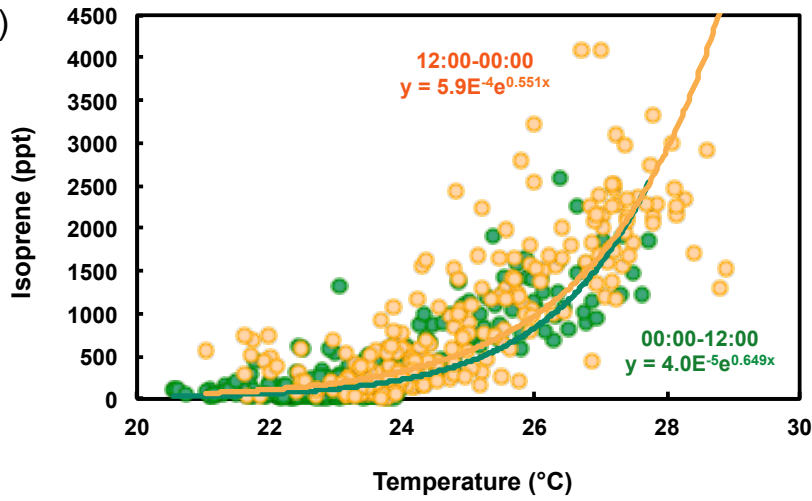

Fig. 5. Correlations between the ambient isoprene mixing ratio with, (a) PAR and (b) temperature, in the morning (between midnight and midday - green circles) and in the afternoon (between midday and midnight - orange circles).

The wind speed at the site was generally lower between sunrise and mid-afternoon, compared to the late-afternoonnight time period (Fig. 3). This suggests that in addition to those environmental factors that directly control emissions (namely PAR and temperature), the wind speed may also impact upon ambient BVOC levels, with reduced wind speeds meaning local emissions were more concentrated in the morning and early afternoon, due to reduced mixing and dilution by regional air. We do note, however, that the wind speed was relatively low for the duration of the OP3 measurement campaign at the Bukit Atur GAW station, and the average diurnal variation was only $\sim 1.5 \mathrm{~m} \mathrm{~s}^{-1}$.

Figure 6 shows the diurnal variability in the relative abundance of each monoterpene. At night, monoterpene emissions were dominated by $\gamma$-terpinene $(\sim 46 \%)$, however during sunlit hours, although $\gamma$-terpinene was still the most abundant monoterpene, its relative contribution was reduced ( $\sim 36 \%$ ), whilst the relative amount of camphene, and to a lesser extent limonene, increased. Between $6 \mathrm{am}$ and $6 \mathrm{pm}$, camphene contributed on average $\sim 24 \%$ of the monoterpene emissions, but supplied only $\sim 14 \%$ at night. Likewise, limonene contributed an average of $\sim 26 \%$ of the total monoterpenes during the day, compared to $\sim 22 \%$ at night.

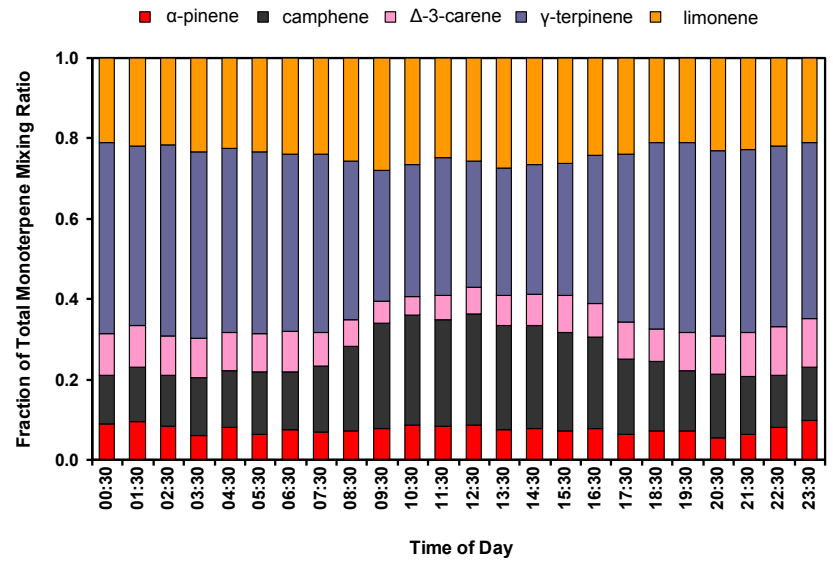

Fig. 6. Average diurnal variation in the relative fractions of the individual monoterpenes $\alpha$-pinene (red), camphene (grey), $\Delta$-3-carene (pink), $\gamma$-terpinene (blue) and limonene (orange), based upon measurements between 23 June-20 July.

In absolute terms, $\alpha$-pinene and $\Delta$-3-carene were present at much lower levels compared to the other monoterpenes however, like $\gamma$-terpinene, the fraction supplied by $\Delta$-3-carene did decrease during the day (from $\sim 10 \%$ at night to $\sim 7 \%$ during daytime). The average contribution from $\alpha$-pinene of $\sim 8 \%$ was approximately constant over a $24 \mathrm{~h}$.

Table 3 summarises Spearman's rank correlation coefficients which quantify the extent of correlation between the atmospheric mixing ratios of selected VOCs. The strong correlations between certain BVOCs are indicative of a common source, and/or similar atmospheric removal rates. Camphene and limonene demonstrated the strongest correlation $(\rho=0.95)$, whilst both were also well correlated with $\alpha$ pinene $(\rho=0.81$ and 0.77 for camphene and limonene, respectively). In addition, $\alpha$-pinene, camphene and limonene all showed significant correlations with isoprene. Since the particularly strong correlation between camphene and limonene cannot be explained by comparable loss rates (as the atmospheric lifetime of limonene with respect to $\mathrm{OH}$ is 3 times shorter than that of camphene - Atkinson and Arey, 2003), we assume that in this case the apparent similarities in their atmospheric mixing ratios are most likely driven by a substantial common (local) emission source.

$\mathrm{Li}$ et al. (2008) also observed strong correlations between limonene, camphene and $\alpha$-pinene, in emissions from Chinese pine (Pinus tabulaeformis), and inferred that biosynthesis of these monoterpenes may be controlled by a common metabolic pathway. However, in contrast to our measurements, they did not find that these monoterpenes were also strongly correlated with isoprene.

Methacrolein was most strongly correlated with its atmospheric precursor isoprene, although the relatively weak correlation (compared to those between the primary BVOCs) is most likely a result of a slight time-delay between primary 
Table 3. Spearman's rank correlation coefficients to illustrate the extent of correlation between monoterpenes, isoprene, methacrolein and ethane. VOC-monoterpene correlations are derived based upon 478 data pairs. All other VOC correlations are derived from 534 data pairs. The strongest correlations are highlighted in bold.

\begin{tabular}{lrrrrrrr}
\hline & $\alpha$-pinene & camphene & $\Delta$-3-carene & $\gamma$-terpinene & limonene & methacrolein & ethane \\
\hline isoprene & $\mathbf{0 . 7 8}$ & $\mathbf{0 . 7 6}$ & 0.61 & 0.61 & $\mathbf{0 . 7 9}$ & 0.52 & -0.16 \\
$\alpha$-pinene & & $\mathbf{0 . 8 1}$ & 0.49 & 0.60 & $\mathbf{0 . 7 7}$ & 0.32 & -0.07 \\
camphene & & & 0.49 & 0.62 & $\mathbf{0 . 9 5}$ & 0.20 & 0.21 \\
$\Delta$-3-carene & & & & 0.33 & 0.58 & 0.48 & -0.07 \\
$\gamma$-terpinene & & & & & $\mathbf{0 . 7 7}$ & 0.27 & 0.20 \\
limonene & & & & & & 0.22 & 0.0 \\
methacrolein & & & & & & -0.23 \\
\hline
\end{tabular}

emission of isoprene, and its gas phase oxidation to produce methacrolein (apparent in the respective diurnal average mixing ratio profiles, Fig. 3). The non-biogenic VOCs (e.g. ethane) showed no significant correlation with temperature or PAR (Table 2), or with any BVOC (Table 3).

\subsection{VOC carbon budget and $\mathrm{OH}$ reactivity within the natural rainforest}

The relative contributions from each VOC to the atmospheric carbon mass budget and to boundary layer $\mathrm{OH}$ removal have been calculated for the tropical boundary layer at Bukit Atur, based upon our observations. The relative contributions from isoprene, monoterpenes, OVOCs, alkenes and alkanes are shown in Fig. 7. It should be noted that the list of VOC species measured by our system (Table 1) is not exhaustive, and contributions from additional VOCs not measured in this work will likely alter the overall contributions of OVOCs, alkenes and alkanes to some extent. In particular, as the GCFID system deployed in this study was unable to resolve the ethanol and methyl vinyl ketone (MVK) peaks, these VOCs were not included in the following calculations. Comparison of our methacrolein observations with the combined methacrolein and MVK mixing ratio reported by Langford et al. (2010) suggests approximately equal mixing ratios of MVK and methacrolein.

As there was strong diurnal variability in many BVOC mixing ratios, these analyses have been separated for daytime (06:00 a.m.-06:00 p.m.) and night time (06:00 p.m.06:00 a.m.) observations. These analyses are based upon data from OP3-III only, since this was the period with the most comprehensive VOC measurements.

The calculated average daytime total VOC carbon concentration during OP3-III was $6150 \mathrm{ngC} \mathrm{m}^{-3}$ - approximately double the average night time value $\left(3130 \mathrm{ngC} \mathrm{m}^{-3}\right)$. Figure 7 shows that during sunlit hours, isoprene provided the largest single source of volatile organic carbon, with an average contribution of $36 \%$, compared to a $14 \%$ average daytime source from monoterpenes and $27 \%$ from OVOCs (sum of methacrolein, methanol, acetone and acetaldehyde).
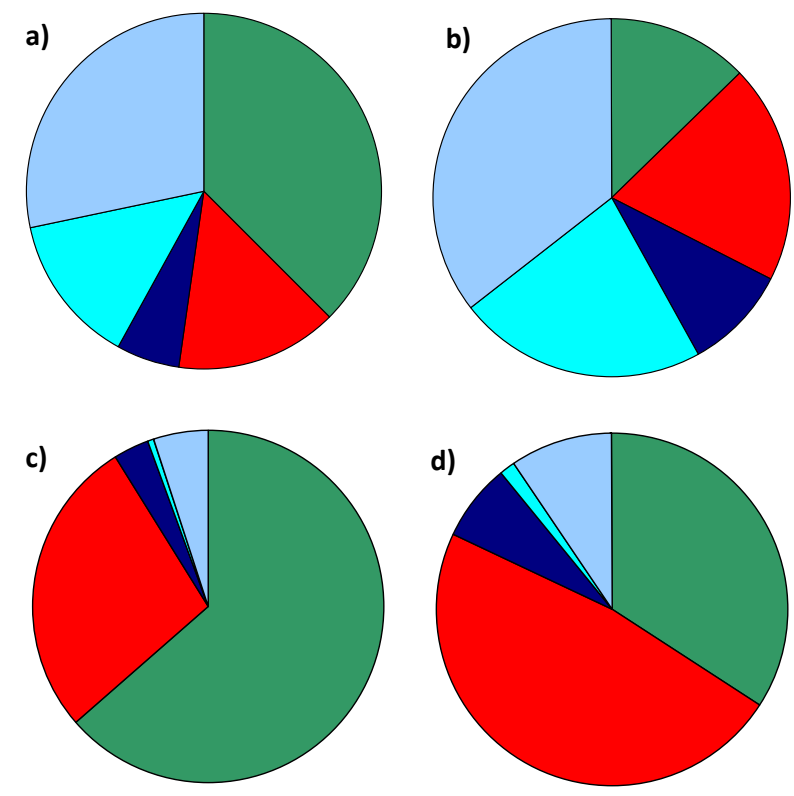

Fig. 7. Plots (a) and (b) represent the average instantaneous fraction of the total volatile organic carbon comprised of isoprene, monoterpenes, alkenes, alkanes and OVOCs in ground-level air at Bukit Atur, during the day (06:00 a.m.-06:00 p.m.; a) and night time (06:00 p.m.-06:00 a.m.; b). Plots (c) and (d) demonstrate the relative VOC reactivity with respect to $\mathrm{OH}$ for each VOC class during day time (c) and at night (d), based upon the rate constants from Atkinson et al. (1986); Atkinson (1997); Atkinson and Arey (2003).

Around midday, isoprene supplied up to $70 \%$ of boundary layer volatile organic carbon, while within an hour after sunrise and before sunset, the contribution from isoprene was as little as $5 \%$. During the night, the absolute concentrations of isoprene, monoterpenes and OVOCs were reduced relative to the daytime, and the fraction of volatile organic carbon supplied as OVOCs and monoterpenes increased, to $35 \%$ and $20 \%$ respectively, while the isoprene contribution decreased, to $13 \%$. 

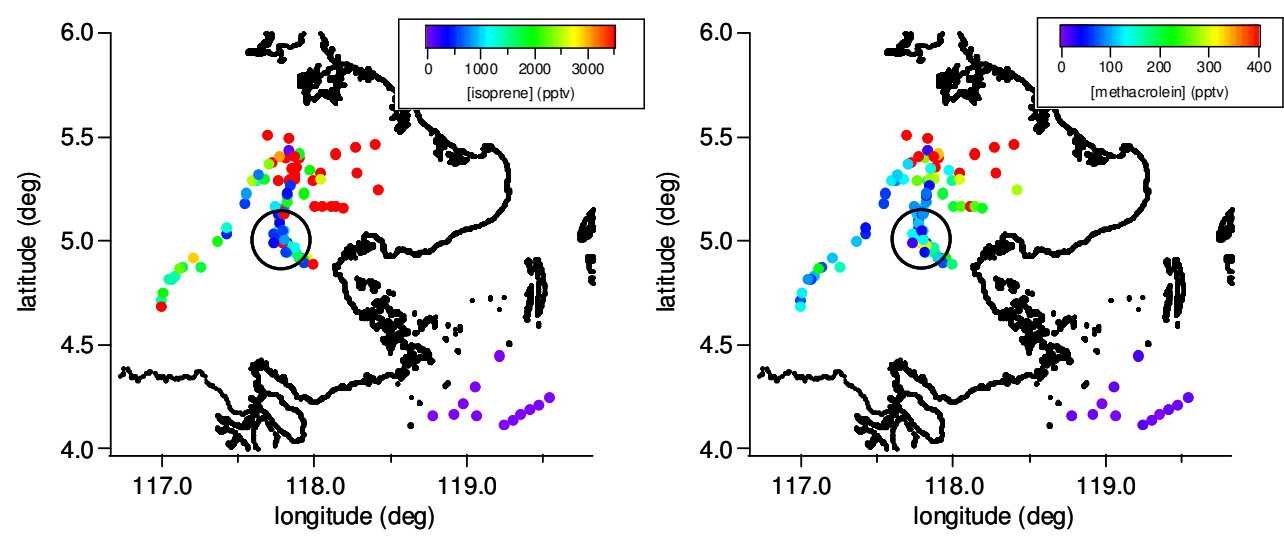

Fig. 8. Regional variations in isoprene and methacrolein mixing ratios across Borneo (black open circle highlights the Danum Valley conservation area), for all samples collected on board the aircraft, below $500 \mathrm{ft}$. (VOC analysis was carried out by GC-FID analysis of whole air samples).

The reactivity of each VOC with respect to $\mathrm{OH}$ was calculated for each instantaneous measured mixing ratio as the product of the VOC concentration (converted from ppt to molec $\mathrm{cm}^{-3}$ ) and the relevant published rate constant, $k_{\mathrm{OH}}$ $\left(\mathrm{cm}^{3} \mathrm{molec}^{-1} \mathrm{~s}^{-1}\right)$ (Atkinson et al., 1986; Atkinson, 1997; Atkinson and Arey, 2003). Figure 7 shows the average day and night resolved distribution of the total $\mathrm{OH}$ reactivity with respect to VOCs, based upon all measurements from OP3-III. Night time reactivities have been determined in addition to the daytime values since $\mathrm{OH}$ was intermittently above instrument detection limits during the night at Bukit Atur (Whalley et al., 2011). During the day, isoprene contributed on average $\sim 64 \%$ of $\mathrm{OH}$ removal by VOCs, while the total combined contribution from the monoterpenes was $\sim 27 \%$. The OVOCs, alkanes and alkenes all made smaller contributions $(\sim 5, \sim 0.5$ and $\sim 3.5 \%$ respectively). During the night, however, the potential removal of $\mathrm{OH}$ was dominated by the monoterpenes, with a total $\mathrm{OH}$ reactivity of $\sim 48 \%$, compared to $\sim 34 \%$ from isoprene. The total average daytime $\mathrm{OH}$ reactivity based upon the VOCs reported here was $3.6 \mathrm{~s}^{-1}$. The contribution to $\mathrm{OH}$ reactivity from the individual monoterpenes increased in the order $\alpha$-pinene $<\Delta$-3-carene $<$ camphene $<$ limonene $<\gamma$-terpinene.

\subsection{Regional differences in VOC composition and OH reactivity}

Strong regional differences were apparent in the isoprene and methacrolein mixing ratios over Borneo. The black open circle in Fig. 8 indicates the location of the Danum Valley conservation area; the area to the north east of Danum Valley is predominantly oil palm plantations, and this area is characterised by regionally higher levels of isoprene and methacrolein, compared to the natural forest (Fig. 8) (Misztal et al., 2010). Conversely acetylene, used as a tracer of anthropogenic pollution, was more uniform across both

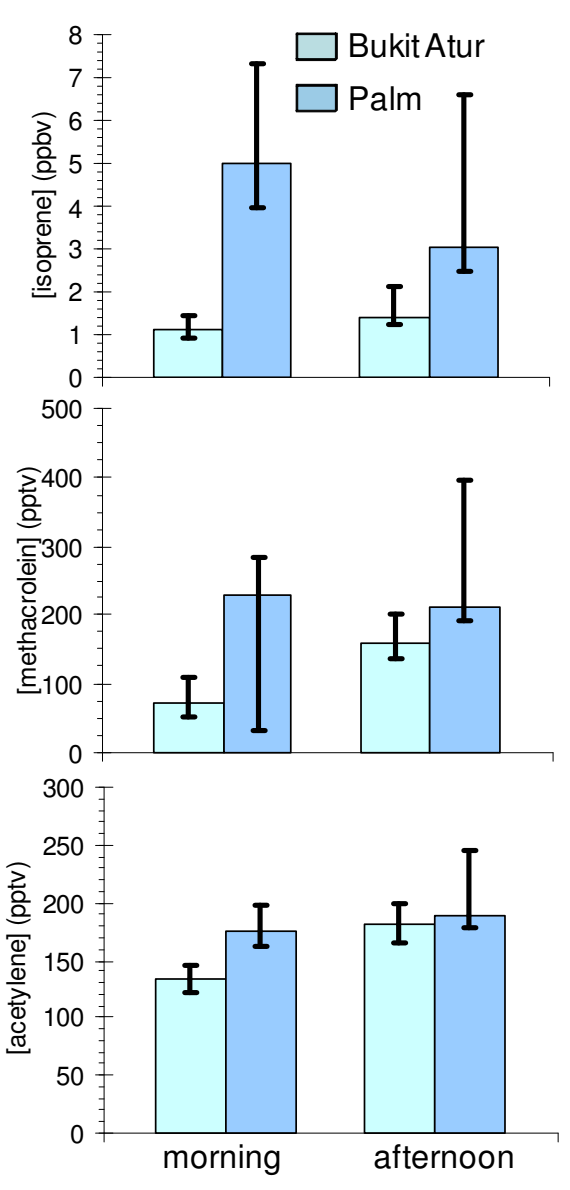

Fig. 9. Mean mixing ratios of isoprene, methacrolein and acetylene (with range expressed as 25th and 75th percentiles) observed within the boundary layer $(<500 \mathrm{ft})$ above the Danum Valley natural rainforest in the vicinity of the Bukit Atur site, and over the oil palm plantations. The particularly large range of isoprene and methacrolein mixing ratios at both locations reflects the substantial diurnal variability in ambient levels of these gases. 
the plantation and natural forest regions (Fig. 9). Figure 9 highlights differences in the mean morning and afternoon mixing ratios of isoprene, methacrolein and acetylene in air above the natural rainforests of Danum Valley and over the oil palm plantations. Figure 9 also shows the typical range (25th-75th percentiles) of mixing ratios observed throughout the morning (06:00 a.m.-12:00 noon) and afternoon (12:00 noon-06:00 p.m.) periods in both locations. The large range in observed isoprene and methacrolein mixing ratios in both regions is a consequence of the substantial diurnal variation in levels of these BVOCs.

The total VOC $\mathrm{OH}$ reactivity over the oil palm region was greater than that above the natural rainforest, with total reactivities of 4.3 and $14.4 \mathrm{~s}^{-1}$ over the Bukit Atur site and palm regions, respectively. A more detailed description of the regional variations in boundary layer isoprene over Borneo during OP3 is given elsewhere (Hewitt et al., 2009, 2010), while the broader aspects of the impacts of land-use change on atmospheric composition and emissions in southeast Asia are discussed in Fowler et al. (2010) and MacKenzie et al. (2011).

\section{Summary}

VOC observations in the atmosphere above Borneo's Danum Valley rainforest demonstrate that isoprene provides the single largest volatile carbon source in this region, whilst monoterpenes were found to contribute a comparatively smaller, yet still significant fraction. During sunlit hours, the atmospheric isoprene mixing ratio was, on average, almost four times larger than the combined monoterpene mixing ratio, however monoterpenes were found to make a substantial contribution both to the carbon mass budget (comprising a daytime average of $\sim 14 \%$ of carbon by mass supplied to the atmosphere as VOCs) and in the removal of the atmospheric oxidant $\mathrm{OH}$ (contributing $\sim 27 \%$ of $\mathrm{VOC}$ initiated $\mathrm{OH}$ destruction). In the absence of sunlight, however, the relative importance of monoterpenes increased, with an average night time combined mixing ratio double that of isoprene, and accounting for, on average, $48 \%$ of the total nocturnal $\mathrm{OH}$ reactivity.

Since the individual monoterpenes have differing $\mathrm{OH}$ reaction rate constants, speciated monoterpene observations are preferable over some techniques which report only the total monoterpene signal, in order to achieve the most accurate interpretation of their significance as an atmospheric carbon source, as well as determining their impact upon $\mathrm{OH}$ reactivity. The relative abundance of the individual monoterpenes in this study generally increased in the order $\alpha$-pinene $\sim \Delta$ 3 -carene $<$ camphene $<$ limonene $<\gamma$-terpinene. As a result of their abundance and relatively high $\mathrm{OH}$ reactivities, limonene and $\gamma$-terpinene accounted for, on average, $86 \%$ of day time monoterpene removal of $\mathrm{OH}$ from this rainforest region. Despite their comparable atmospheric lifetimes, the fraction of the total monoterpenes comprised of $\gamma$-terpinene was reduced during the day, whilst the relative fraction of limonene increased. Further investigation is required to clarify whether there is some level of light-controlled release of limonene and camphene in the vicinity of Bukit Atur, or whether their apparently strong correlations with PAR are merely an artefact of the correlation between PAR and ambient air temperature. Overall, the monoterpene mixing ratios in the Danum Valley conservation area were generally more consistent with a temperature-controlled emission pathway, whilst isoprene mixing ratios also demonstrated strong light dependence.

Acknowledgements. The authors would like to thank staff at FAAM, Avalon and Direct Flight Ltd for their support during the campaign, the National Centre for Atmospheric Science (NCAS) and the Facility for Ground based Atmospheric Measurements (FGAM) for funding and provision of instruments, and the staff of the Danum Valley Field Centre and Bukit Atur GAW station. We also thank the University of Leeds for providing $\mathrm{OH}$ measurements, and the Centre for Ecology and Hydrology (CEH), Edinburgh, for PAR and temperature data. This is paper 526 of the Royal Society's South-East Asian Rainforest Research Programme.

Edited by: R. MacKenzie

\section{References}

Atkinson, R.: Gas-phase troposphere chemistry of volatile organic compounds: 1. Alkanes and Alkenes, J. Phys. Chem. Ref. Data, 26(2), 215-290, 1997.

Atkinson, R. and Arey, J.: Gas-phase tropospheric chemistry of biogenic volatile organic compounds: a review, Atmos. Environ., 2, S197-S219, 2003.

Atkinson, R., Aschmann, S. M., and Pitts, J. N.: Rate constants for gas-phase reactions of the $\mathrm{OH}$ radical with a series of monoterpenes at $294 \pm 1 \mathrm{~K}$, Int. J. Chem. Kinet., 18, 287-299, 1986.

Calvert, J. G., Atkinson, R., Kerr, J.A., Madronich, S., Moortgat, G. K., Wallington, T. J., and Yarwood, G.: The Mechanisms of Atmospheric Oxidation of the Alkenes, Oxford University Press, New York, NY, 552 pp., 2000.

Fowler, D., Nemitz, E., Misztal, P., Di Marco, C., Skiba, U., Ryder, J., Helfter, C., Cape, N., Owen, S., Dorsey, J., Gallagher, M. W., Coyle, M., Phillips, G., Davison, B., Langford, B., MacKenzie, A. R., Muller, J., Siong, J., Pyle, J. A., and Hewitt, C. N.: Effects of land use on trace gas emissions and deposition in Borneo: comparing atmosphere-surface exchange over oil palm plantations with a rainforest, Phil. Trans. Roy. Soc. Lond., invited submission for a special issue on Tropical forests, land-use change and climate, in press, Phil. Trans. Roy. Soc. Lon., 2011.

Fuentes, J. D., Lerdau, M., Atkinson, R., Baldocchi, D., Bottenheim, J. W., Ciccioli, P., Lamb, B., Geron, C., Gu, L., Guenther, A., Sharkey, T. D., and Stockwell, W.: Biogenic Hydrocarbons in the Atmospheric Boundary Layer: A Review, B. Am. Meteorol. Soc., 81(7), 1537-1575, 2000.

Greenberg, J. P., Guenther, A., Zimmerman, P., Baugh, W., Geron, C., Davis, K., Helmig, D., and Klinger, L. F.: Tethered balloon 
measurements of biogenic VOCs in the atmospheric boundary layer, Atmos. Environ., 33, 855-867, 1999.

Grinspoon, J., Bowman, W. D., and Fall, R.: Delayed Onset of Isoprene Emission in Developing Velvet Bean (Mucuna sp.) Leaves, Plant Physiol., 97, 170-174, 1991.

Guenther, A.: Are plant emissions green?, Nature, 452, 701-702, 2008.

Guenther, A., Hewitt, C. N., Erickson, D., Fall, R., Geron, C., Graedel, T., Harley, P., Klinger, L., Lerdau, M., McKay, W. A., Pierce, T., Scholes, B., Steinbrecher, R., Tallamraju, R., Taylor, J., and Zimmerman, P.: A global model of natural volatile organic compound emissions, J. Geophys. Res., 100, 8873-8892, 1995.

Guenther, A., Geron, C., Pierce, T., Lamb, B., Harley, P., and Fall, R.: Natural emissions of non-methane volatile organic compounds, carbon monoxide, and oxides of nitrogen from North America, Atmospheric Environment, 34, 2205-2230, 2000.

Guenther, A., Hewitt, C. N., Karl, T., Harley, P., and Reeves, C.: Biogenic VOC emissions from African, American and Asian tropical rainforests, Eos Trans. AGU, 89(53), Fall Meet. Suppl., Abstract A14C-04, 2008.

Hewitt, C. N., MacKenzie, A. R., Di Carlo, P., Di Marco, C. F., Dorsey, J. R., Evans, M., Fowler, D., Gallagher, M.W., Hopkins, J. R., Jones, C. E., Langford, B., Lee, J. D., Lewis, A. C., Lim, S. F., McQuaid, J., Misztal, P., Moller, S. J., Monks, P. S., Nemitz, E., Oram, D. E., Owen, S. M., Phillips, G. J., Pugh, T. A. M., Pyle, J. A., Reeves, C. E., Ryder, J., Siong, J., Skiba, U. and Stewart, D. J.: Nitrogen management is essential to prevent tropical oil palm plantations from causing ground-level ozone pollution, P. Natl. Acad. Sci., 106(44), 18447-18451, 2009.

Hewitt, C. N., Lee, J. D., MacKenzie, A. R., Barkley, M. P., Carslaw, N., Carver, G. D., Chappell, N. A., Coe, H., Collier, C., Commane, R., Davies, F., Davison, B., DiCarlo, P., Di Marco, C. F., Dorsey, J. R., Edwards, P. M., Evans, M. J., Fowler, D., Furneaux, K. L., Gallagher, M., Guenther, A., Heard, D. E., Helfter, C., Hopkins, J., Ingham, T., Irwin, M., Jones, C., Karunaharan, A., Langford, B., Lewis, A. C., Lim, S. F., MacDonald, S. M., Mahajan, A. S., Malpass, S., McFiggans, G., Mills, G., Misztal, P., Moller, S., Monks, P. S., Nemitz, E., Nicolas-Perea, V., Oetjen, H., Oram, D. E., Palmer, P. I., Phillips, G. J., Pike, R., Plane, J. M. C., Pugh, T., Pyle, J. A., Reeves, C. E., Robinson, N. H., Stewart, D., Stone, D., Whalley, L. K., and Yin, X.: Overview: oxidant and particle photochemical processes above a south-east Asian tropical rainforest (the OP3 project): introduction, rationale, location characteristics and tools, Atmos. Chem. Phys., 10, 169-199, doi:10.5194/acp-10169-2010, 2010.

Holzke, C., Dindorf, T., Kesselmeier, J., Kuhn, U., and Koppmann, R.: Terpene emissions from European beech (Fagus sylvatica L.): Pattern and emission behaviour over two vegetation periods, J. Atmos. Chem., 55, 81-102, doi:10.1007/s10874-006-9027-9, 2006.

Hopkins, J. R., Lewis, A. C., and Read, K. A.: A two-column method for long-term monitoring of non-methane hydrocarbons (NMHCs) and oxygenated volatile organic compounds (oVOCs), J. Environ. Monit., 4, 1-7, 2002.

Hopkins, J. R., Jones C. E., and Lewis, A. C.: A dual channel gas chromatograph for atmospheric analysis of volatile organic compounds including oxygenated and monoterpene compounds, J.
Environ. Monit., doi:10.1039/c1em10050e, 2011.

IPCC (Intergovernmental Panel on Climate Change), coordinating lead authors Ehhalt, D. and Prather, M.: Chapter 4, Atmospheric chemistry and green house gases. In: IPCC Third Assessment Report-Climate Change 2001: The Scientific Basis. IPCC, Geneva, 238-287, 2001.

Karl, T., Guenther, A., Yokelson, R. J., Greenberg, J., Potosnak, M., Blake, D. R., and Artaxo, P.: The tropical forest and fire emissions experiment: Emission, chemistry, and transport of biogenic volatile organic compounds in the lower atmosphere over Amazonia, J. Geophys. Res., 112, D18302, doi:10.1029/2007JD008539, 2007.

Kesselmeier, J. and Staudt, M.: Biogenic volatile organic compounds (VOC): An overview on emission, physiology and ecology, J. Atmos. Chem., 33(1), 23-88, 1999.

Kesselmeier, J., Kuhn, U., Wolf, A., Andreae, M. O., Ciccioli, P., Brancaleoni, E., Frattoni, M., Guenther, A., Greenberg, J., De Castro Vasconcellos, P., Telles de Oliva, Tavares, T., and Artaxi, P.: Atmospheric volatile organic compounds (VOC) at a remote tropical forest site in central Amazonia, Atmos. Environ., 34, 4063-4072, 2000.

Kuhn, U., Rottenberger, S., Biesenthal, T., Wolf, A., Schebeske, G., Ciccioli, P., Brancaleoni, E., Frattoni, M., Tavares, T. M., and Kesselmeier, J.: Isoprene and monoterpene emissions of Amazonian tree species during the wet season: Direct and indirect investigations on controlling environmental functions, J. Geophys. Res., 107(D20), 8071, doi:10.1029/2001JD000978, 2002.

Langford, B., Misztal, P. K., Nemitz, E., Davison, B., Helfter, C., Pugh, T. A. M., MacKenzie, A. R., Lim, S. F., and Hewitt, C. N.: Fluxes and concentrations of volatile organic compounds from a South-East Asian tropical rainforest, Atmos. Chem. Phys., 10, 8391-8412, doi:10.5194/acp-10-8391-2010, 2010.

Lelieveld, J., Butler, T. M., Crowley, J. N., Dillon, T. J., Fischer, H., Ganzeveld, L., Harder, H., Lawrence, M. G., Martinez, M., Taraborrelli, D., and Williams, J.: Atmospheric oxidationcapacity sustained by a tropical forest, Nature, 452, 737-740, 2008.

Li, D. W., Shi, Y., He, X. Y., Chen, W., and Chen, X.: Volatile organic compound emissions from urban trees in Shenyang, China, Botanical Studies, 49, 67-72, 2008.

MacKenzie, A. R., Langford, B., Pugh, T. A. M., Robinson, N., Misztal, P. K., Heard, D. E., Lee, J. D., Lewis, A. C., Jones, C. E., Hopkins, J. R., Philips, G., Monks, P. S., Karunaharan, A., Hornsby, K. E., Nicolas-Perea, V., Coe, H., Whalley, L. K., Edwards, P. M., Evans, M. J., Stone, D., Ingham, T., Commane, R., Furneaux, K. L., McQuaid, J., Nemitz, E., Yap Kok Seng, Fowler, D., Pyle, J. A., and Hewitt, C. N.: The atmospheric chemistry of trace gases and particulate matter emitted by different land uses in Borneo, Philos. T. Roy. Soc. London, in press, 2011.

Misztal, P. K., Owen, S. M., Guenther, A. B., Rasmussen, R., Geron, C., Harley, P., Phillips, G. J., Ryan, A., Edwards, D. P., Hewitt, C. N., Nemitz, E., Siong, J., Heal, M. R., and Cape, J. N.: Large estragole fluxes from oil palms in Borneo, Atmos. Chem. Phys., 10, 4343-4358, doi:10.5194/acp-10-4343-2010, 2010.

Motulsky, H.: Chapter 37 from Intuitive Biostatistics, Oxford University Press, ISBN 0-19-508607-4, 1995.

Noe, S. M., Ciccioli, P., Brancaleoni, E., Loreto, F., and Niinemets, U.: Emissions of monoterpenes linalool and ocimene respond differently to environmental changes due to differences 
in physico-chemical characteristics, Atmos. Environ., 40, 46494662, 2006.

Padhy, P. K. and Varshney, C. K.: Emission of volatile organic compounds (VOC) from tropical plant species in India, Chemosphere, 59, 1643-1653, 2005.

Pearson, G., Davies, F., and Collier, C.: Remote sensing of the tropical rain forest boundary layer using pulsed Doppler lidar, Atmos. Chem. Phys., 10, 5891-5901, doi:10.5194/acp-10-58912010, 2010.

Pike, R. C., Lee, J. D., Young, P. J., Carver, G. D., Yang, X., Warwick, N., Moller, S., Misztal, P., Langford, B., Stewart, D., Reeves, C. E., Hewitt, C. N., and Pyle, J. A.: $\mathrm{NO}_{\mathrm{x}}$ and $\mathrm{O}_{3}$ above a tropical rainforest: an analysis with a global and box model, Atmos. Chem. Phys., 10, 10607-10620, doi:10.5194/acp10-10607-2010, 2010.

Pugh, T. A. M., MacKenzie, A. R., Hewitt, C. N., Langford, B., Edwards, P. M., Furneaux, K. L., Heard, D. E., Hopkins, J. R., Jones, C. E., Karunaharan, A., Lee, J., Mills, G., Misztal, P., Moller, S., Monks, P. S., and Whalley, L. K.: Simulating atmospheric composition over a South-East Asian tropical rainforest: performance of a chemistry box model, Atmos. Chem. Phys., 10, 279-298, doi:10.5194/acp-10-279-2010, 2010.

Saxton, J. E., Lewis, A. C., Kettlewell, J. H., Ozel, M. Z., Gogus, F., Boni, Y., Korogone, S. O. U., and Serça, D.: Isoprene and monoterpene measurements in a secondary forest in northern Benin, Atmos. Chem. Phys., 7, 4095-4106, doi:10.5194/acp-74095-2007, 2007.
Sharkey T. D. and Yeh, S. S.: Annual Review of Plant Physiology and Plant Molecular Biology, Isoprene emissions from plants, Annu. Rev., 52, 407-436, 2001.

Simpson D., Winiwarter, W., Borjesson, G., Cinderby, S., Ferreiro, A., Guenther, A., Hewitt, C. N., Janson, R., Khalil, M. A. K., Owen, S., Pierce, T. E., Puxbaum, H., Shearer, M., Skiba, U., Steinbrecher, R., Tarrason, L., and Oquist, M. G.: Inventorying emissions from nature in Europe, J. Geophys. Res., 104(D7), 8113-8152, 1999.

Whalley, L. K., Edwards, P. M., Furneaux, K. L., Goddard, A., Ingham, T., Evans, M. J., Stone, D., Hopkins, J. R., Jones, C. E., Karunaharan, A., Lee, J. D., Lewis, A. C., Monks, P. S., Moller, S. J., and Heard, D. E.: Quantifying the magnitude of a missing hydroxyl radical source in a tropical rainforest, Atmos. Chem. Phys. Discuss., 11, 5785-5809, doi:10.5194/acpd11-5785-2011, 2011.

Wildermuth, M. C. and Fall, R.: Light-dependent isoprene emission - Characterization of a thylakoid-bound isoprene synthase in Salix discolor chloroplasts, Plant Physiol., 112, 171-182, 1996.

Wilske, B., Caoa, K.-F., Schebeskeb, G. Chena, J.-W. Wanga, A., and Kesselmeier, J.: Isoprenoid emissions of trees in a tropical rainforest in Xishuangbanna, SW China, Atmos. Environ., 41, 3748-3757, 2007. 